\title{
Sedentary behavior is associated with physical activity, functional capacity, and a history of stroke in patients with heart failure. A cross-sectional study
}

\author{
Ila MF Bendassolli ${ }^{1}$, Antonio G Oliveira ${ }^{1}$, Eduardo C Costa ${ }^{1}$, Dyego LB de Souza ${ }^{1}$, Eulália MC Maia ${ }^{1}$ \\ ${ }^{1}$ Federal University of Rio Grande do Norte, UFRN, Natal, RN, Brazil
}

\begin{abstract}
Aims: Sedentary behavior (SB) has emerged as an important risk factor for poor health. Evidence showed that patients with heart failure (HF) exhibit high levels of SB, and that high SB increases mortality among such patients. We aimed to identify factors associated with SB in HF patients. Methods: A cross-sectional study was carried out with adults with HF and categorized under New York Heart Association (NYHA) functional class I-III. Sociodemographic, clinical, and health information were gathered. Evaluation of SB (by sitting time) and moderate-to-vigorous physical activity (MVPA) was performed by self-reported measures. Functional capacity was assessed using the Duke Activity Status Index. Simple and multivariate linear regression analyses were performed to identify the most suitable predictive model. Results: The sample $(\mathrm{n}=80)$ comprised predominantly of patients in functional class I, men, and with an average age of 50.8 years. Time spent on SB totaled to $7.69 \pm 2.35 \mathrm{~h} /$ day. Weekly volume of MVPA, functional capacity, and previous stroke were predictors of higher SB. Using simple linear regression analysis, the variables body mass index, quality of life, NYHA functional class, total comorbidities, dyslipidemia, MVPA in the leisure domain, and the use of diuretics, statins, and sildenafil were shown to have a statistically significant association with SB. Conclusion: In patients with HF, a longer time spent in SB was associated with low volumes of MVPA, low functional capacity, and history of stroke. More studies are needed to corroborate these findings.
\end{abstract}

Keywords: sedentary time, physical activity, health behavior, cardiovascular diseases, nonexercising, aging.

\section{Introduction}

Heart failure (HF) is a debilitating, progressive, and highmortality clinical syndrome ${ }^{1}$. Patients with HF feature reduced physical capacity, which can lead to reduction in their daily activities, decrease in the level of physical activity, and increased periods of sedentary behavior (SB), resulting in adverse health consequences ${ }^{2-5}$.

A growing number of studies suggest that high SB results in deleterious metabolic and cardiovascular effects ${ }^{6-10}$. In addition, high SB is importantly associated with early mortality ${ }^{7,11,12}$. SB is defined as the time spent in activities of low energy expenditure ( $\leq 1.5$ METs - Metabolic Equivalent of Task), performed in the sitting, reclining, or lying position during the waking period ${ }^{13-15}$. Thus, sitting time, the generic denomination for $\mathrm{SB}{ }^{13}$, has been utilized to evaluate SB of individuals in the domestic environment, at work, or during leisure, such as watching TV.

Patients with HF exhibit high SB $(\sim 10 \mathrm{~h} / \text { day })^{16-18}$. Doukky et al. ${ }^{19}$ observed that with increasing sedentary time, risk of all-cause mortality and cardiac causes gradually increases in patients with HF. These patients generally do not meet the recommendations of moderate-to-vigorous physical activity (MVPA) ${ }^{3,4,18,20}$ of at least $30 \mathrm{~min} /$ day; this insufficient activity may be an aggravating factor given that SB is especially detrimental in individuals who perform low physical activity levels ${ }^{21,22}$. Thus, a common phenotype is observed in HF patients: high SB (i.e., sitting time) along with low physical activity (i.e., no MVPA).

Although an association exists between SB and increased risk of morbidity and mortality among patients with HF, the factors associated with high prevalence of SB in this population remain unknown. Thus, identifying factors associated with SB in patients with HF can guide clinical management of these patients with regard to non-pharmacological strategies. This study aims to analyze the association between sociodemographic, clinical, and health characteristics and SB in patients with HF.

\section{Methods}

\section{Study design and participants}

This research is a cross-sectional study carried out between February 2015 and April 2016 in an outpatient clinic specializing in treatment of HF in northeastern Brazil (Federal University of Rio Grande do Norte). The study was approved by the research ethics committee of the institution (number $660.366 \mathrm{HUOL} /$ UFRN), and all participants signed a free and informed consent form in accordance with the Helsinki Declaration. Inclusion criteria were as follows: patients diagnosed with $\mathrm{HF}$, as determined by the Framingham criteria along with the support of diagnostic tests, more than 18 years old, classified under functional class I to III of New York Heart Association (NYHA), and clinically stable for at least three months. Exclusion criteria were as follows: patients using wheelchair or unable to move independently or who were cognitively unable to respond to the questionnaires. Patients who did not have time for answering the questionnaires 
(physical activity and functional capacity), which depended on a single evaluator, were also excluded. All patients were evaluated by the same medical staff and received regular medical therapy ${ }^{23}$.

\section{Procedures}

The study participants were selected according to the order of completion of clinical consultations, which were conducted once a week during afternoons. After the medical consultation, the patients who fulfilled the criteria for participation in the study were referred to the responsible researcher who then invited them to participate in the study. Sociodemographic information was obtained directly from each participant, and clinical and health information were provided by the ambulatory medical team or collected through consultation from patients' medical records. Quality of life (QoL) score was collected through a questionnaire, which was administered by face-to-face interviews accomplished within the same month of collection of other information by two trained applicators who were not part of the research. MVPA and functional capacity were measured using specific questionnaires that were administered through an interview conducted by a trained applicator after the patient's medical consultation. SB was also evaluated through an interview conducted by the same applicator on the same day of the application of the physical activity and functional capacity questionnaires.

\section{Measures}

\section{Sociodemographic, clinical, and health characteristics}

We collected data on sex, age, schooling (years of study), and occupation (yes / no); functional class according to NYHA; left ventricular ejection fraction determined by echocardiography; body mass index (BMI- $\mathrm{Kg} / \mathrm{m}^{2}$ ) obtained by objective measurement of weight and height of participants; etiology of the disease (ischemic/nonischemic); medications in use; and comorbidities (total number of comorbidities, systemic arterial hypertension, type 2 diabetes mellitus, dyslipidemia, chronic obstructive pulmonary disease, atrial fibrillation, acute myocardial infarction, coronary artery disease, and stroke).

\section{QoL and functional capacity}

QoL was determined by the Minnesota Living with Heart Failure Questionnaire (MLHFQ) ${ }^{24}$. MLHFQ is a questionnaire composed of 21 items measuring physical, psychological, and socioeconomic dimensions. The scores range from 0 to 105 . Higher scores indicate worse QoL. Functional capacity was measured using the Duke Activity Status Index (DASI) ${ }^{25}$, a questionnaire developed to evaluate perceived functional capacity of individuals with cardiovascular disease. DASI is a simple, short, and quick application questionnaire. The scores range from 0 to 58.2. Higher scores imply increased functional capacity ${ }^{26}$. The questionnaire showed good reproducibility in patients with HF (an intraclass correlation coefficient of $0.95 ; p<0.0001)^{27}$. A strong correlation $(\mathrm{r}=0,81 ; \mathrm{p}<0,01)$ was also observed between DASI and VO2peak (peak oxygen uptake) ${ }^{26}$.

\section{$S B$}

SB was evaluated for total time (hours) spent in activities performed in the sitting, reclining, or lying down position during periods of awakeness in the day. To facilitate the accounting of the daily hours spent in sedentary activities ${ }^{28}$, patients were asked to describe their daily routines involving such activities, with consideration of the domains in the domestic environment, at work, at leisure, and during transportation, keeping in mind a usual day of the week. Patients who reported sleeping during the day were requested to also account for this time. Postures of sitting, reclining, and lying down were recently established as indicators of SB ${ }^{15}$, and the evaluation of total daily SB while considering the domains in which it occurs (composite measure) can provide a more precise measure when compared with assessment by a single-item ${ }^{29}$.

\section{$M V P A$}

To evaluate weekly volume of MVPA, the International Physical Activity Questionnaire (IPAQ) ${ }^{30}$ long form was used. This questionnaire is used to determine the level of physical activity in adult populations. In the Brazilian population, IPAQ showed good reliability and acceptable validity when compared with objective measures of physical activity ${ }^{31}$. This questionnaire measured MVPA in four specific domains: at work, in the domestic environment, during leisure and exercise, and in active transportation.

Continuous score (MET-min/week) was used to quantify the total volume of weekly physical activity, which was later categorized based on the recommendations of physical activity for this population 5 of at least 30 min of MVPA on most days of the week corresponding to approximately $600 \mathrm{MET}-\mathrm{min} /$ week. This variable was then dichotomized at $<600 \mathrm{MET}$-min/week and $\geq 600 \mathrm{MET}$-min/week. To evaluate the impact of regular exercise on SB, ie., non-incidental physical activity ${ }^{32}$, the MVPA in the leisure and exercise domain was included in analysis (as categorical variable: yes or no).

\section{Statistical analysis}

Data analysis was performed using Stata 11 software (Stata Corporation, College Station, TX, USA). Data are presented descriptively by mean and standard deviation or by absolute 
and relative frequencies. A simple linear regression analysis was conducted to evaluate the relationship between sociodemographic, clinical, and health variables and SB to identify variables of statistical significance to construct the multiple linear regression model. Variables with $\mathrm{p} \leq 0.10$ were included in the multivariate model, and regression was performed through step-by-step retrograde method. Statistical significance considered for the model was set at $5 \%(\mathrm{p}<0.05)$. The covariates included in the multivariate model were BMI, MLHFQ, DASI, NYHA functional class, DM2, DLP, stroke, total comorbidities, diuretics, statins, sildenafil, weekly volume of MVPA, and MVPA in the domain of leisure and exercise. Existence of multicollinearity among independent variables was tested through tolerance, and homoscedasticity was verified by residue chart. A sample size of 80 patients would allow the identification of associations with a Pearson's correlation coefficient greater than 0.30 with $80 \%$ power ${ }^{33}$. The following formula was used for calculation:

$$
n=\left[\frac{(\mathrm{Z} \alpha+\mathrm{Z} \beta)}{0.5 \times \ln [(1+r))(((1-r)}\right]^{2}+3
$$

\section{Results}

The study population consisted of 80 patients. Table 1 summarizes the sociodemographic, clinical, health characteristics, and SB and MVPA of the patients. Participants reported an average of $7.69 \pm 2.35$ $\mathrm{h}$ of SB a day, and more than half did not meet the recommendations of MVPA ${ }^{5}$. Patients who performed MVPA volumes $\geq 600$ METs$\min /$ week $(\mathrm{n}=37 ; 46 \%)$ presented an average weekly volume of $1287.4 \pm 681.8$ METs-min. The same proportion was observed for those performing MVPA in the leisure and exercise domain. In this specific domain, a mean volume of $662.4 \pm 355.1 \mathrm{METs}-\mathrm{min} /$ week was observed.

Table 1. Characterization of the sample according to sociodemographic, clinical and health characteristics, and sedentary behavior and physical activity $n=80$

\begin{tabular}{lc}
\hline \multicolumn{2}{l}{ Sociodemographic characteristics } \\
\hline Male & $47(58.8)$ \\
Age & $50.79 \pm 14.43$ \\
Schooling - years of study & $6.6 \pm 4.3$ \\
Individuals with occupation & $19(23.8)$ \\
\hline Clinical and health characteristics & $27.64 \pm 6.08$ \\
\hline BMI & $28.5 \pm 23.20^{*}$ \\
MLHFQ & $34.8 \pm 13.7$ \\
DASI - Mets & $39.03 \pm 13.89 *$ \\
\% Left Ventricular Ejection Fraction & $17(21.3)^{*}$ \\
Etiology ischemic
\end{tabular}

\begin{tabular}{|c|c|}
\hline \multicolumn{2}{|l|}{ NYHA functional class } \\
\hline I & $42(52.5)$ \\
\hline II & $29(36.3)$ \\
\hline III & $9(11.3)$ \\
\hline \multicolumn{2}{|l|}{ Comorbidities } \\
\hline Systemic arterial hypertension & $46(57.5)$ \\
\hline Diabetes mellitus - type 2 & $25(31.3)^{*}$ \\
\hline Dyslipidemia & $17(21.3)^{*}$ \\
\hline Coronary Artery Disease & $15(18.8)$ \\
\hline Acute Myocardial Infarction & $14(17.5)^{*}$ \\
\hline Stroke & $6(7.5)$ \\
\hline Chronic Obstructive Pulmonary Disease & $4(5)$ \\
\hline Atrial Fibrillation & $4(5)^{*}$ \\
\hline Total number of comorbidities & $1.85 \pm 1.37$ \\
\hline \multicolumn{2}{|l|}{ Medications in use } \\
\hline ACE inhibitor or ARB & $77(96.3)$ \\
\hline Beta bloquers & $77(96.3)$ \\
\hline Diuretics & $54(67.5)$ \\
\hline Spironolactone & $44(64.7)$ \\
\hline Statin & $37(46.3)$ \\
\hline Digoxin & $27(33.8)$ \\
\hline Amlodipine & $9(11.3)$ \\
\hline Hydralazine & $8(10)$ \\
\hline Warfarin & $7(8.8)$ \\
\hline Ivabradine & $5(6.3)$ \\
\hline Sildenafil & $3(3.8)$ \\
\hline \multicolumn{2}{|l|}{ Sedentary behavior and Physical activity } \\
\hline SB - hours/day & $7.69 \pm 2.35$ \\
\hline MVPA $\geq 600 \mathrm{METs}-\mathrm{min} /$ week & $37(46.3)$ \\
\hline Weekly volume -METs-min & $1287.4 \pm 681.8$ \\
\hline MVPA Leisure and exercise domain (yes) & $37(46.3)$ \\
\hline Weekly volume -METs-min & $662.4 \pm 355.1$ \\
\hline
\end{tabular}

Note: Values are expressed as mean $\pm \mathrm{SD}$ or $\mathrm{n}(\%)$. BMI - Body Mass Index; NYHA - New York Heart Association; MLHFQ - Minnesota Living with Heart Failure Questionnaire; DASI - Duke Activity Status Index; MVPA -Moderate to vigorous physical activity; ACE - Angiotensin-converting enzyme; ARB Angiotensin-II receptor blocker.

*missing data - LVEF: 1; MLHFQ: 5; etiology ischemic: 2; DM2, DLP, IAM e FA: 1

In univariate analysis (Table 2), BMI, MLHFQ score, NYHA functional class, total comorbidities, DLP, stroke, and the use of diuretics and statins showed a significant positive association with SB. MVPA $\geq 600$ METs-min/week, MVPA in the leisure and exercise domain, functional capacity, and the use of sildenafil were negatively associated with SB. In the multivariate regression model (Table 2), SB remained significantly associated with MVPA $\geq 600 \mathrm{METs}-\mathrm{min} /$ week, functional capacity, and stroke. Age, a potential confounding variable, was included in the final model.

After adjusting for age, weekly volume of MVPA presented strong evidence of negative association with SB. Patients who exhibited 
MVPA volumes $\geq 600 \mathrm{METs}-\mathrm{min} /$ week presented approximately $2 \mathrm{~h}$ and $27 \mathrm{~min}$ less of daily time in SB (95\% confidence interval: -3.33 to $-1.58 \mathrm{~h}$ ). The observed correlation between functional capacity and SB demonstrated a reduction of $2.8 \mathrm{~min}$ in SB at each point of increase in DASI score. Lastly, the patients suffering from stroke presented $1 \mathrm{~h}$ and $35 \mathrm{~min}$ more SB per day. The final model, composed by covariates MVPA $\geq 600$ METs-min/week, DASI, stroke, and age, explains $52.3 \%$ of the variability in SB of these patients.

Table 2. Bivariate and multivariate associations of sedentary behavior and the covariates of the study.

\begin{tabular}{|c|c|c|c|c|c|c|c|c|}
\hline \multicolumn{9}{|l|}{ SB (hours/day) } \\
\hline \multirow{3}{*}{$\begin{array}{c}\text { Covariates } \\
\text { Gender (male) }\end{array}$} & \multicolumn{4}{|c|}{ Univariate analysis } & \multicolumn{4}{|c|}{ Multivariate analysis } \\
\hline & \multirow{2}{*}{$\begin{array}{c}\text { Coefficient } \\
0.654\end{array}$} & \multicolumn{2}{|c|}{ CI 95\% } & \multirow{2}{*}{$\frac{p}{0.222}$} & \multirow[t]{2}{*}{ Coefficient } & \multicolumn{2}{|c|}{ CI 95\% } & \multirow[t]{2}{*}{$\mathrm{p}$} \\
\hline & & -0.403 & 1.712 & & & & & \\
\hline Age & 0.016 & -0.020 & 0.053 & 0.372 & -0.013 & -0.043 & -0.016 & 0.370 \\
\hline BMI & 0.098 & 0.014 & 0.182 & 0.023 & & & & \\
\hline Schooling & -0.014 & -0.137 & 0.108 & 0.815 & & & & \\
\hline Occupation & -0.971 & -2.187 & 0.245 & 0.116 & & & & \\
\hline MLHFQ & 0.033 & 0.011 & 0.055 & 0.004 & & & & \\
\hline DASI & -0.082 & -0.116 & -0.048 & $<0.001$ & -0.047 & -0.081 & -0.012 & 0.008 \\
\hline LVEF & -0.005 & -0.043 & 0.034 & 0.805 & & & & \\
\hline Etiology ischemic & 0.860 & 0.293 & 2.524 & 0.784 & & & & \\
\hline \multicolumn{9}{|l|}{ Functional class } \\
\hline NYHA 2 & 1.204 & 0.108 & 2.301 & 0.041 & & & & \\
\hline NYHA 3 & 1.595 & -0.073 & 3.264 & & & & & \\
\hline \multicolumn{9}{|l|}{ Comorbidities } \\
\hline $\mathrm{SAH}$ & -0.075 & -1.155 & 1.005 & 0.890 & & & & \\
\hline DM 2 & 1.048 & -0.072 & 2.168 & 0.066 & & & & \\
\hline DLP & 1.651 & 0.380 & 2.922 & 0.012 & & & & \\
\hline Stroke & 2.326 & 0.387 & 4.266 & 0.019 & 1.593 & 0.113 & 3.073 & 0.035 \\
\hline COPD & 0.070 & -2.359 & 2.499 & 0.954 & & & & \\
\hline $\mathrm{AF}$ & 1.913 & -0.477 & 4.303 & 0.115 & & & & \\
\hline AMI & 0.732 & -0.653 & 2.117 & 0.296 & & & & \\
\hline CAD & -0.108 & -1.454 & 1.239 & 0.874 & & & & \\
\hline Total of comorbidities & 0.391 & 0.010 & 0.773 & 0.044 & & & & \\
\hline \multicolumn{9}{|l|}{ Use of medication } \\
\hline ACE inhibitor & -0.073 & -1.159 & 1.013 & 0.893 & & & & \\
\hline $\mathrm{ARB}$ & -0.087 & -1.199 & 1.024 & 0.876 & & & & \\
\hline Beta bloquers & -0.325 & -3.091 & 2.442 & 0.816 & & & & \\
\hline Diuretics & 1.303 & 0.220 & 2.387 & 0.019 & & & & \\
\hline Spironolactone & 0.508 & -0.588 & 1.605 & 0.359 & & & & \\
\hline Statin & 1.084 & 0.058 & 2.110 & 0.039 & & & & \\
\hline Digoxin & 0.304 & -0.806 & 1.414 & 0.587 & & & & \\
\hline Amlodipine & -0.023 & -1.687 & 1.640 & 0.978 & & & & \\
\hline Hydralazine & -0.069 & -1.822 & 1.683 & 0.937 & & & & \\
\hline Warfarin & 0.342 & -1.517 & 2.202 & 0.715 & & & & \\
\hline Ivabradine & -0.520 & -2.689 & 1.649 & 0.634 & & & & \\
\hline Sildenafil & -2.792 & -5.487 & -0.097 & 0.042 & & & & \\
\hline $\begin{array}{c}\text { MVPA } \\
\geq 600 \mathrm{METs}\end{array}$ & -3.140 & -3.921 & -2.358 & $<0.001$ & -2.457 & -3.334 & -1.580 & $<0.001$ \\
\hline $\begin{array}{l}\text { Leisure/exercise } \\
\text { domain }\end{array}$ & -1.961 & -2.917 & -1.006 & $<0.001$ & & & & \\
\hline
\end{tabular}

Note: CI - confidence interval; BMI - Body Mass Index; NYHA - New York Heart Association; MLHFQ - Minnesota Living with Heart Failure Questionnaire; DASI - Duke Activity Status Index; LVEF - Left Ventricular Ejection Fraction; SAH - Systemic Arterial Hypertension; DM2 - type 2 Diabetes Mellitus; DLP Dislipidemia; CAD - Coronary Artery Disease; AMI - Acute Myocardial Infarction; COPD - Chronic Obstructive Pulmonary Disease; AF - Atrial Fibrillation; ACE - Angiotensin-converting enzyme; ARB - Angiotensin-II receptor blocker; MVPA - Moderate to vigorous physical activity. 


\section{Discussion}

The results of this study showed that the characteristics indicative of or related to physical condition of patients with $\mathrm{HF}$ are associated with their SB. Low weekly volumes of MVPA, low functional capacity, and history of stroke were significantly associated with a longer time spent in SB in these patients. To our knowledge, this study was the first to investigate the factors associated with SB in patients with $\mathrm{HF}$.

The mean SB observed in our sample was relatively lower than that observed in other studies, which used objective measures ${ }^{16,18}$. However, the value corroborates with the mean observed in the study by Borland, Rosenkvist, $\mathrm{Cider}^{17}$, who also used self-reported measures. The time spent on SB was significantly low among patients who complied with weekly MVPA recommendations. MVPA performed only in leisure and exercise domain exerted no influence on SB pattern. However, a relatively low mean weekly volume was observed among patients who performed MVPA in this specific domain. Indeed, HF patients spent an average of $2.1 \mathrm{~h} /$ week in MVPA in the leisure and exercise domain ${ }^{18}$. This result suggests that for these patients, engagement in incidental MVPA (such as domestic activities, at work, and during transportation) ${ }^{32}$ can be important for both reduction of their SB and achievement of satisfactory levels of MVPA according to recommendations of health guidelines ${ }^{5}$.

To date, literature presents no consensus with respect to the relationship between MVPA and SB, and little available data support the results obtained in this study, particularly in the HF population. A systematic review of cross-sectional and prospective design studies in the adult population revealed nine articles that assessed SB based on the total sitting time and moderate physical activity. Among these studies, only three showed a negative relationship with physical activity, whereas the others presented no relation ${ }^{34}$.

Considering that patients with HF already feature reduced physical capacity ${ }^{2}$, the negative association between MVPA and SB observed in this study can be explained by the better physical capacity of patients who performed MVPA volumes $\geq 600 \mathrm{METs}-\mathrm{min} /$ week given that adequate volumes of MVPA contribute to the maintenance of physical capacity of these patients ${ }^{4,5}$, thus favoring a more active daily routine. Garet et al. ${ }^{35}$ observed that physical capacity, measured objectively $\left(\mathrm{VO}_{2}\right.$ peak), was highly correlated with daily energy expenditure of HF patients, suggesting that low physical capacity contributes to a pattern of low daily energy expenditure, that is, more time spent in SB. This finding is corroborated by those of Toth, Gottlieb, Fisher, Poehlman ${ }^{36}$, who, using objective measures of energy expenditure, also identified a positive relationship between daily energy expenditure and $\mathrm{VO}_{2}$ peak in these patients. Both studies also observed an inverse relationship between daily energy expenditure and NYHA functional class, suggesting that worse functional status/higher severity of the disease may increase the time spent in SB. In our sample, NYHA functional class was also positively associated with
SB. However, this association was not observed in the final model. The low number of NYHA class III participants may have influenced this result.

In this study, the functional capacity evaluated by DASI showed a negative association with SB in the final model. This result reinforces our hypothesis to explain the negative association found between MVPA and SB. As discussed previously, in HF patients, a better physical capacity contributes to more independence in performing daily activities (light intensity $)^{2,5}$, which can consequently lead to a reduction in the time spent in $\mathrm{SB}^{6}$. Epidemiological evidence has suggested an inverse relationship between sedentary time and light-intensity physical activity ${ }^{13}$.

An intervention study with HF patients observed a reduction in sitting time with increased physical capacity after participating in an exercise program ${ }^{17}$. Interestingly, the authors also observed a significant increase in self-reported physical activity in domains not captured by a pedometer, suggesting that patients became more active in their daily activities. This phenomenon should be further investigated in future studies given that the reduction of SB through light-intensity activities may be especially important for HF patients because not all of them can achieve adequate levels of weekly MVPA ${ }^{18,20}$.

The positive association observed between stroke and $\mathrm{SB}$ is possibly related to greater physical disability, slow walking speed of stroke patients, and less time spent in MVPA ${ }^{37}$. Although DLP and DM2 comorbidities have not shown statistically significant association with SB in the final model, both are metabolic diseases closely related to deleterious effects of $\mathrm{SB}^{6,9,10}$. We reasonably believe that an increase in our sample could lead to a significant result of these variables in the final model.

The relationship between SB and QoL among HF patients was recently investigated by Edwards and Loprinzi ${ }^{38}$. The authors observed that SB was significantly associated with worsening of health-related QoL, and that such association was independent of moderate physical activity. Our findings partially converge with their results. Univariate analysis revealed that longer time spent in SB was associated to worse QoL. However, such an association was not independent of MVPA. In our sample, the association observed between QoL and SB was no longer associated in the multivariate model, which was composed by the covariates MVPA, DASI, stroke, and age. When we adjusted the model by MVPA only, the association between QoL and SB was also not statistically significant ( $p=0.30$ data not shown), suggesting that the association between QoL and SB depends on MVPA. This divergence between the findings may be related to differences in the volumes of physical activity observed in each case. In the study by Edwards and Loprinzi ${ }^{38}$, the mean of moderate physical activity was significantly lower than that observed in our sample. The authors acknowledge that the volume of moderate physical activity found in their research was consistently below recommendations of physical activity, and these conditions may have influenced their results. 
Finally, literature has pointed out a strong and consistent correlation between age and $\mathrm{SB}^{39}$. In our sample, we observed no evidence of the association between age and SB. However, the sample consisted of relatively young patients. Future studies with larger and more heterogeneous samples can better investigate this relationship in populations of patients with HF. Regardless, we have opted to include age in the final model as this variable is a biologically plausible confounder in this association and also contributed to better adjustment of the model.

This study features some limitations that must be considered. All exposures (MVPA, SB, and functional capacity) were assessed using self-reported measures, which have been shown to underestimate such behavior. To minimize such measurement bias, the interview for SB assessment, our major exposure of interest, was conducted with consideration for various dimensions of $\mathrm{SB}{ }^{28,29}$. Administration of MVPA, functional capacity, and SB questionnaires was performed by an interviewer who was not blinded to the study objectives and thus may be subject to information bias. A further limitation of this study is related to our decision of measuring SB taking into account only a usual day of the week. It is probable that the amount of time spent in SB varies between weekdays and weekends, and consequently, the total time spent in SB may have been underestimated in our study. Additionally, the findings described in this study should be interpreted considering the intrinsic limitations of the cross-sectional design employed, which prevented us from establishing causal relationships. For example, results cannot possibly determine whether lower functional capacity led to prolonged sitting time, or whether prolonged sitting time led to lower physical capacity in these patients. Lastly, generalization of our results may be limited considering the sample of a single outpatient clinic. Despite these limitations, the study contributes to the scarce literature dealing with the topic of SB in the context of HF.

\section{Conclusion}

Findings from the present study suggest that longer time spent in SB of patients with HF is associated with low volumes of weekly MVPA, low functional capacity, and previous stroke. More studies are needed to corroborate these findings. Studies using larger samples and analyzing additional factors, such as psychological and environmental variables, which can be potentially associated with SB in these patients can better explain this behavior in this population.

\section{Acknowledgements}

We thank the entire staff of the Heart Failure Ambulatory of HUOL/UFRN - Brazil, where this research was carried out, for their accommodation and technical support.

\section{References}

1. Go AS, Mozaffarian D, Roger VL, Benjamin EJ, Berry JD, Blaha MJ, et al. Heart disease and stroke statistics 2014 update: a report from the American Heart Association. Circulation. 2013;129(3):e28-e292.

2. Yancy CW, Jessup M, Bozkurt B, Butler J, Casey DE, Jr., Drazner MH, et al. ACCF/AHA guideline for the management of heart failure: a report of the American College of Cardiology Foundation/American Heart Association Task Force on Practice Guidelines. JAm Coll Cardiol. 2013;62(16):e147-239.

3. Dontje ML, van der Wal MHL, Stolk RP, Brugemann J, Jaarsma T, Wijtvliet P, et al. Daily Physical Activity in Stable Heart Failure Patients. J Cardiovasc Nurs. 2014;29(3):218-26.

4. Jehn M, Schmidt-Trucksass A, Schuster T, Weis M, Hanssen H, Halle M, et al. Daily walking performance as an independent predictor of advanced heart failure: Prediction of exercise capacity in chronic heart failure. Am Heart J. 2009;157(2):292-8.

5. Piepoli MF, Corra U, Benzer W, Bjarnason-Wehrens B, Dendale P, Gaita D, et al. Secondary prevention through cardiac rehabilitation: physical activity counselling and exercise training: key components of the position paper from the Cardiac Rehabilitation Section of the European Association of Cardiovascular Prevention and Rehabilitation. Eur Heart J. 2010;31(16):1967-74.

6. Healy GN, Wijndaele K, Dunstan DW, Shaw JE, Salmon J, Zimmet PZ, et al. Objectively Measured Sedentary Time, Physical Activity, and Metabolic Risk: The Australian Diabetes, Obesity and Lifestyle Study (AusDiab). Diabetes Care. 2008;31(2):369-71.

7. Katzmarzyk PT, Church TS, Craig CL, Bouchard C. Sitting time and mortality from all causes, cardiovascular disease, and cancer. Med Sci Sports Exerc. 2009;41(5):998-1005.

8. Petersen C, Bauman A, Grønbæk M, Helge J, Thygesen L, Toulstrup J. Total sitting time and risk of myocardial infarction, coronary heart disease and all-cause mortality in a prospective cohort of Danish adults. Int J Behav Nutr Physical Activity. 2014;11(13):1-13.

9. Proper KI, Singh AS, van Mechelen W, Chinapaw MJ. Sedentary behaviors and health outcomes among adults: a systematic review of prospective studies. Am J Prev Med. 2011;40(2):174-82.

10. Thorp AA, Owen N, Neuhaus M, Dunstan DW. Sedentary behaviors and subsequent health outcomes in adults a systematic review of longitudinal studies, 1996-2011. Am J Prev Med. 2011;41(2):207-15.

11. Biswas A, Oh PI, Faulkner GE, Bajaj RR, Silver MA, Mitchell MS, et al. Sedentary time and its association with risk for disease incidence, mortality, and hospitalization in adults: a systematic review and meta-analysis. Ann Intern Med. 2015;162(2):123-32. 
12. van der Ploeg HP, Tien C, Korda RJ, Banks E, Bauman A. Sitting Time and All-Cause Mortality Risk in 222497 Australian Adults. Arch Intern Med. 2012;172(6):494-500.

13. Owen N, Healy GN, Matthews CE, Dunstan DW. Too much sitting: the population health science of sedentary behavior. Exerc Sport Sci Rev. 2010;38(3):105-13.

14. Young DR, Hivert MF, Alhassan S, Camhi SM, Ferguson JF, Katzmarzyk PT, et al. Sedentary Behavior and Cardiovascular Morbidity and Mortality: A Science Advisory From the American Heart Association. Circulation. 2016;134(13):e262-79.

15. Tremblay MS, Aubert S, Barnes JD, Saunders TJ, Carson V, Latimer-Cheung AE, et al. Sedentary Behavior Research Network (SBRN) - Terminology Consensus Project process and outcome. Int J Behav Nutr Phys Act. 2017;14(1):75.

16. Alosco ML, Spitznagel MB, Miller L, Raz N, Cohen R, Sweet LH, et al. Depression Is Associated With Reduced Physical Activity in Persons With Heart Failure. Health Psychol. 2012;31(6):754-62.

17. Borland M, Rosenkvist A, Cider A. A group-based exercise programme did not improve physical activity in patients with chronic heart failure and comorbidity: A Randomized controlled trial. J Rehabil Med. 2014;46(5):461-7.

18. Evenson KR, Butler EN, Rosamond WD. Prevalence of physical activity and sedentary behavior among adults with cardiovascular disease in the United States. J Cardiopulm Rehabil Prev. 2014;34(6):406-19.

19. Doukky R, Mangla A, Ibrahim Z, Poulin MF, Avery E, Collado FM, et al. Impact of Physical Inactivity on Mortality in Patients With Heart Failure. Am J Cardiol. 2016;117(7):1135-43.

20. Jaarsma T, Stromberg A, Ben Gal T, Cameron J, Driscoll A, Duengen HD, et al. Comparison of self-care behaviors of heart failure patients in 15 countries worldwide. Patient Educ Couns. 2013;92(1):114-20.

21. Buman MP, Hekler EB, Haskell WL, Pruitt L, Conway TL, Cain KL, et al. Objective light-intensity physical activity associations with rated health in older adults. Am J Epidemiol. 2010;172(10):1155-65.

22. Ekelund U, Steene-Johannessen J, Brown W, Fagerland M, Owen N, Powell K, et al. Does physical activity attenuate, or even eliminate, the detrimental association of sitting time with mortality? A harmonised meta-analysis of data from more than 1 million men and women. The Lancet. 2016;27:7-16.

23. Bochi EA, Marcondes-Braga FG, Bacal F, Ferraz AS, Albuquerque D, Rodrigues D, et al. Sociedade Brasileira de Cardiologia. Atualização da Diretriz Brasileira de Insuficiência Cardíaca Crônica. Arq Bras Cardiol. 2012;98(1 supl. 1):1-33.

24. Carvalho V, Guimarães G, Carrara D, Bacal F, Bochi EA. Validação da Versão em Português do Minnesota Living with Heart Failure Questionnaire. Arq Bras Cardiol. 2009;93(1):39-44.
25. Coutinho-Myrrha M, Dias R, Fernandes A, Araújo C, Hlatky M, Pereira D, et al. Duke Activity Status Index for cardiovascular diseases: Validation of the portuguese Translation. Arq Bras Cardiol. 2014;102(4):383-90.

26. Hlatky M, Boineau R, Higginbotham M, Lee K, Mark D, Califf $\mathrm{R}$, et al. A brief self-administered questionnaire to determine functional capacity (The Duke Activity Status Index). Am J Cardiol. 1989;64:651-4.

27. Arena R, Humphrey R, Peberdy M. Using the Duke Activity Status Index in heart failure. J Cardiopulm Rehabil. 2002;22(2):93-5.

28. Rowe D, Kemble C, Robinson T, Mahar M. Daily walking in older adults: day-to-day variability and criterionreferenced validity of total daily step counts. J Phys Act Health. 2007;4(4):434-46.

29. Healy GN, Clark BK, Winkler EA, Gardiner PA, Brown WJ, Matthews CE. Measurement of adults' sedentary time in population-based studies. Am J Prev Med. 2011;41(2):216-27.

30. Craig CL, Marshall AL, Sjostrom M, Bauman AE, Booth $\mathrm{ML}$, Ainsworth BE, et al. International physical activity questionnaire: 12-country reliability and validity. Med Sci Sports Exerc. 2003;35(8):1381-95.

31. Matsudo S, Araujo T, Matsudo V, Andrade D, Andrade E, Oliveira L, et al. Questionário Internacional de Atividade Física (IPAQ): Estudo de validade e reprodutibilidade no Brasil. Atividade Física e Saúde. 2001;6(2):5-18.

32. Strath SJ, Kaminsky LA, Ainsworth BE, Ekelund U, Freedson PS, Gary RA, et al. Guide to the assessment of physical activity: Clinical and research applications: a scientific statement from the American Heart Association. American Heart Association Physical Activity Committee of the Council on Lifestyle and Cardiometabolic Health and Cardiovascular, Exercise, Cardiac Rehabilitation and Prevention Committee of the Council on Clinical Cardiology, and Council on Cardiovascular and Stroke Nursing. Circulation. 2013;128(20):2259-79.

33. Hulley S, Cummings S, Browner W, Grady D, Newman T. Designing clinical research: an epidemiologic approach. Appendix 6C. 4th ed. Philadelphia, PA: Lippincott Williams \& Wilkins; 2013. p. 79.

34. Rhodes RE, Mark RS, Temmel CP. Adult sedentary behavior: a systematic review. Am J Prev Med. 2012;42(3):e3-28.

35. Garet M, Barthelemy JC, Degache F, Costes F, Da-Costa A, Isaaz K, et al. A questionnaire-based assessment of daily physical activity in heart failure. Eur J Heart Fail. 2004;6(5):577-84.

36. 36. Toth MJ, Gottlieb SS, Fisher ML, Poehlman ET. Daily Energy Requirements in Heart Failure Patients. Metabolis. 1997;146(11):1294-8.

37. Paul L, Brewster S, Wyke S, Gill J, Alexander G, Dybus A, et al. Physical activity profiles and sedentary behaviour in people following stroke: a cross-sectional study. Disabil Rehabil. 2016;38(4):362-7. 
38. Edwards MK, Loprinzi PD. Sedentary behavior \& healthrelated quality of life among congestive heart failure patients. Int J Cardiol. 2016;220:520-3.

39. Matthews CE, Chen KY, Freedson PS, Buchowski MS, Beech BM, Pate RR, et al. Amount of time spent in sedentary behaviors in the United States, 2003-2004. Am J Epidemiol. 2008;167(7):875-81.

\section{Corresponding author}

Ila MF Bendassolli

Coronel Costa Pinheiro, n. 1506 Natal/RN, Brazil

E-mail: ilabenda@ufrn.edu.br
Manuscript received on January 30, 2018

Manuscript accepted on May 28, 2018

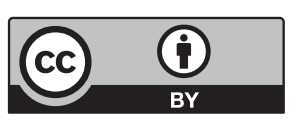

Motriz. The Journal of Physical Education. UNESP. Rio Claro, SP, Brazil - eISSN: 1980-6574 - under a license Creative Commons - Version 3.0 